\title{
Sediment Sources and Transport Pathway Identification Based on Grain-Size Distributions on the SW Coast of Portugal
}

\author{
Xiaoqin $\mathrm{Du}^{1}$, Cristina Gama ${ }^{2}$, James T. Liu ${ }^{1, *}$, and Paulo Baptista ${ }^{3}$ \\ ${ }^{I}$ Department of Oceanography, National Sun Yat-Sen University, Kaohsiung, Taiwan, R.O.C. \\ ${ }^{2}$ C.G.E, Universidade de Évora Colégio Luís Verney, Rua Romão Ramalho, Évora, Portugal \\ ${ }^{3}$ Department Geosciences and Centre for Environmental and Marine Studies CESAM, University of Aveiro, Aveiro, Portugal
}

Received 23 April 2013, revised 30 March 2015, accepted 30 March 2015

\begin{abstract}
Espichel-Sines is an embayed coast in SW Portugal, consisting of two capes at both extremities, a tidal inlet and associated ebb tidal delta, a barrier spit, sandy beaches, sea cliffs, and a submarine canyon. Beach berm, backshore, near shore and inner shelf sediment samples were taken. Samples were analyzed for their grain-size compositions. This study ranks the hypothetical sediment sources influences on the sediment distributions in the study area using the multivariate Empirical Orthogonal Function (EOF) techniques. Transport pathways in this study were independently identified using the grain size trend analysis (GSTA) technique to verify the EOF findings. The results show that the cliff-erosion sediment is composed of pebbles and sand and is the most important sediment source for the entire embayment. The sediment at the inlet mouth is a mixture of pebbles, sand, silt, and clay, which is a minor sediment source that only has local influence. The overall grain-size distributions on the shelf are dominated by the sand except for the high mud content around the tidal delta front in the northern embayment. Sediment transport patterns on the inner shelf at the landward and north sides of the canyon head are landward and northward along the barrier spit, respectively. On the south side of the canyon head, the prevailing sediment transport is seaward. Sediment transport occurs in both directions along the shore.
\end{abstract}

Key words: Sediment grain size, Sediment source, Empirical Orthogonal Function (EOF) analysis, Grain size trend analysis (GSTA), Sediment transport pathway

Citation: Du, X., C. Gama, J. T. Liu, and P. Baptista, 2015: Sediment sources and transport pathway identification based on grain-size distributions on the SW coast of Portugal. Terr. Atmos. Ocean. Sci., 26, 397-409, doi: 10.3319/TAO.2015.03.30.01(TT)

\section{INTRODUCTION}

Each year about $28 \mathrm{Gt}$ of sediment is transported from the land into the oceans (Syvitski 2003). Most of the sediment remains at the river delta or deposited on the continental shelf and along the coast (Syvitski et al. 2003). Sediment transport leads to changes in coastal morphodynamics, coastline positions and grain-size patterns on the sea floor.

The grain size trend establishes the sediment transport pathways (Gao et al. 1994). The geochemical properties of sediment, such as the clay minerals, magnetic minerals, heavy minerals and particle adsorbed radioactive elements and organic substances composition may be used as tracers for sediment transport and deposition (Liu et al. 2009; Xu et al. 2009; Carvalho et al. 2011; Horng and Huh 2011; Huh

\footnotetext{
* Corresponding author

E-mail:james@mail.nsysu.edu.tw
}

et al. 2011). Liu et al. (2000, 2002) also used a methodology that combines a 'filtering' concept and a multivariate analysis technique EOF (Empirical Orthogonal Function) to verify and distinguish the importance of different hypothetical sources. Because sediment grain-size compositions along a transport pathway may result from the mixing of different sediment sources and transport processes (Russell 1939; Swift et al. 1972; Gao et al. 1994), the net sediment transport direction is inferred from the spatial changes in granulometric parameters (i.e., mean grain-size, sorting, and skweness). Many applications were developed based on spatial changes in a single granulometric parameter to indicate net sediment transport paths (Krumbein 1938; Pettijohn and Ridge 1932; Plumley 1948; Pettijohn et al. 1972; McCave 1978). McLaren (1981) was the first to create a sediment transport model based on combined granulometric parameters. His method is an empirical and conceptual 
model hybrid (Wheater et al. 1993; Poizot and Méar 2008). McLaren and Bowles (1985) proposed further development on this model. Based on the McLaren model two-dimensional approaches were proposed by Gao et al. (1991) and Gao and Collins $(1992,1994)$ and Le Roux $(1994 a, b)$. The former proposed trend vectors based on a sampling grid that compares each sample with its neighboring samples within a characteristic distance. The latter assumes that sediment transport takes place across wide unidirectional fronts rather than from point to point. Using geostatistical tools Asselman (1999) modified the Gao-Collins method and implemented a Geographic Information System (GIS) methodology. This method employs initially irregularly spaced data set interpretation to produce a regular grid of grain-size parameters using a Monte Carlo simulation to carry out a statistical test on the trend vectors. Chang et al. (2001) also modified the Gao-Collins method using the significance test on the trend vector length identified at each sampling site instead of the averaged length to avoid identifying trend vectors by chance. Poizot et al. (2006) used geostatistical tools to determine the characteristic distance, which is considered significant in the Gao-Collins method. The latter definition for characteristic distance is more rigorous, taking into account the spatial change in the statistical parameters as the relative change in the parameter value itself. Poizot and Méar (2010) developed new GIS software that accounts for the presence of rocky outcrops in calculating the trend vectors.

Grain-size based sediment transport analyses are widely used in marine depositional environments. They in- clude estuaries (Chang et al. 2001), tidal flats (Wang et al. 2012), beaches (Pedreros et al. 1996), near shore and shore face (Liu et al. 2000; Héquette et al. 2008; Plomaritis et al. 2008), tidal ridges (Gao and Collins 1992; Gao et al. 1994), tidal inlets (Liu and Hou 1997), straits and gulf (Cheng et al. 2004; Ma et al. 2010), submarine canyons (Liu et al. 2002), and coastal seas (Shi et al. 2002). However, sandy near shore and innershelf environments with high wave energy conditions have received little attention.

This study area is an embayed coast partially sheltered by a headland from a predominant high-energy wave field. Hence, sediment deposition and erosion occur synchronously. The goals of this study are to verify hypothetical sediment sources and distinguish their influences within the system and independently identify sediment transport pathways inferred from the spatial changes in the surficial sediment grain-size distribution.

\section{STUDY AREA}

The study area is located between Espichel Cape and Sines Cape in SW Portugal (Fig. 1a), facing the Atlantic Ocean and extending seaward from the shoreline to a depth of 90 m (Fig. 1b). A 35-km long mountain belt (Arrábida Mountain), $500 \mathrm{~m}$ in elevation, is present in the northern extremity (Rebêlo et al. 2009). A barrier spit separates the Sado River Estuary from the Atlantic Ocean is sheltered from the NW wave energy by the Mountain (Fig. 1b). An ebb-tidal delta is well developed on the seaward side of the inlet at Tróia.
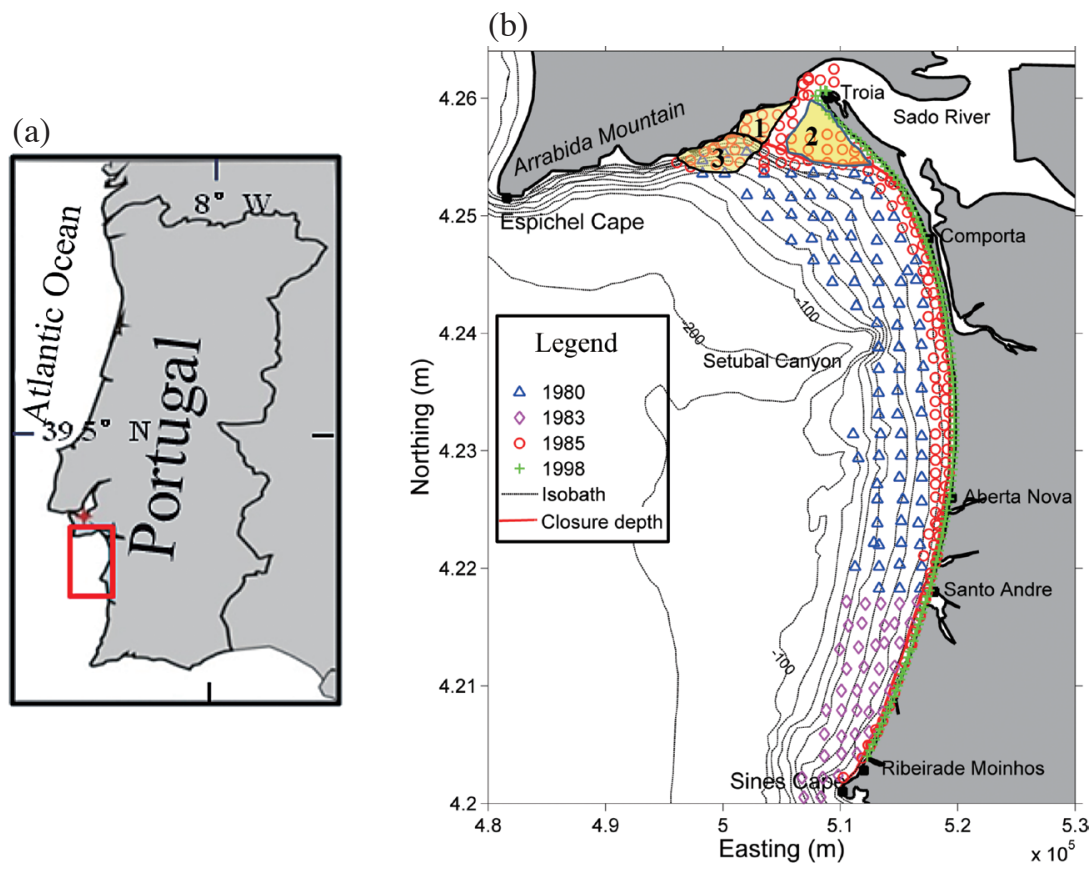

Fig. 1. Map showing the study area location in Portugal (a); Bathymetric map showing sampling locations in different years (b). Regions 1 and 2 are on the ebb-tidal delta and region 3 is located at the delta front near to the northern extremity of the system. The contour intervals of the isobaths on the inner shelf are in $10 \mathrm{~m}$ and the red line shows the location of closure depth. 
The Tróia-Sines embayed coast (TSEC) back shore is delimited by discontinuous dunes, coexisting with cliffs in the south. The latter consist of poorly consolidated Plio-Plistocene detrital deposits, eroded by subaerial processes or gullying. Cliffs covered by dunes exist in some coastal sectors. The Comporta, Aberta Nova, Santo André, and Ribeira de Moinhos beaches are located in front of dunes along TSEC (Fig. 1b), whose beach face gradients range from 0.06 - 0.18 from north to south (Reis and Gama 2010) with increasing seasonal volume changes (Gama 2005). A previous study showed shoreline accretion present in the barrier spit section while shoreline retreat is present in some cliff sections in the southern part of the system (Marques 1999). Dune retreat occurred also at the shoreline between Sines Cape and Santo André (Marques 1999). Setúbal canyon is located in the northern part of the study area with landward terminus at the $60-\mathrm{m}$ isobath and covered by mud (Jouanneau et al. 1998; Gama 2005).

Tides in the study area are semi-diurnal with a range of $1.5 \mathrm{~m}$ (neap) and $3.5 \mathrm{~m}$ (spring) (Jouanneau et al. 1998). Offshore waves have mean significant wave height $\left(\mathrm{H}_{\mathrm{s}}\right)$ and peak period $\left(\mathrm{T}_{\mathrm{p}}\right)$ of $1.7 \mathrm{~m}$ and $10.8 \mathrm{~s}$, respectively. Ten percent of the $\mathrm{H}_{\mathrm{s}}$ values are higher than $3 \mathrm{~m}$ and $60 \%$ of the $T_{p}$ values are between $9-13 \mathrm{~s}$. The peak incident wave directions are NW (77.3\%), W (20\%), SW (2.4\%), and S $(0.2 \%)$ (Costa et al. 2001; Jacob et al. 2009). The northward residual along shore transport rate is $10^{5} \mathrm{~m}^{3}$ year-1 (Gama 2005). Espichel Cape and Arrábida Mountain partly protect the study area. The study area is exposed to swells that come from the W and SW (Quevauviller 1987; Gama 2005; Jacob et al. 2009). Storms from the SW are less frequent but more energetic than storms from other directions (Costa et al. 2001). Based on the wave climate and closure depths the seaward limit of significant profile changes (Nicholls et al. 1998), from north to south are $4.4 \mathrm{~m}$ at Tróia, $7.0 \mathrm{~m}$ at Comporta, $11.0 \mathrm{~m}$ at Aberta Nova, $15 \mathrm{~m}$ at Santo André, and $15.5 \mathrm{~m}$ at Ribeira Moinhos (Gama 2005). The shelf is divided into near shore and offshore zones by the closure depth (Hallermeier 1981), shown in Fig. 1b with red line.

Sado Estuary is $20 \mathrm{~km}$ long and $4 \mathrm{~km}$ wide, with an average depth of $8 \mathrm{~m}$ (Martins et al. 2001). It is a highmesotidal environment, in which the tidal amplitude varies between $1.3 \mathrm{~m}$ during neap and $3.5 \mathrm{~m}$ during spring near the inlet and increases upstream from the estuary (Freitas et al. 2008). Tidal flows suspend the sediment inside the estuary (Vale et al. 1993) and show high levels of $\mathrm{Zn}, \mathrm{Cu}$, and $\mathrm{Cd}$ (Monteiro et al. 1995).

Two major eddies appear (Martins et al. 2001) seaward of the inlet and the typical suspended sediment concentration is $1.4-1.7 \mathrm{mg} \mathrm{L}^{-1}$ (Jouanneau et al. 1998). A $10-30 \mathrm{~m}$ deep-dredged navigational channel extends through the inlet, incising into the ebb-tidal delta. The channel divides the ebb-tidal delta into two sections defined by the 10-m isobath. Region 1 (Fig. 1b) extends from the inlet along the shoreline to the northern edge of the delta and region 2 extends from the inlet opening following the same isobath to the barrier spit (Harzen 1998). The area between the $5-10 \mathrm{~m}$ isobaths experiences much stronger surf than other areas (Harzen 1998). Region 3 (Fig. 1b) is located seaward of region 1 at the delta front and is characterized by a steeper slope.

\section{DATA ACQUISITION AND ANALYTICAL METHODS}

\subsection{Field Work}

The Institute Hydrographic of Portugal sampled sea floor sediment on the inner shelf in 1980, 1983, and 1985, forming one ensemble data set. The 1980 sampling sites were mainly along the inner shelf between $20-80 \mathrm{~m}$ isobaths. The 1983 sampling sites were located in the southern part of the inner shelf. The 1985 sampling sites were located mainly in the near shore area (Fig. 1). An along shore berm and backshore sediment survey at 500-m intervals was conducted during $7-10^{\text {th }}$ of December in 1998 (Gama 2005).

\subsection{Sample Analyses}

Hydrogen peroxide was used to remove shelf sample organic matter. Distilled water was used to wash away the residue. The offshore gravel, sand, silt and clay samples were obtained by wet sieving, using sieves of $-2 \varnothing(4 \mathrm{~mm})$ and $4 \varnothing(0.0625 \mathrm{~mm})$. Further analysis of each of these fractions was carried out using different methods: (1) Gravel fraction: sieving at $1 \varnothing$ intervals; (2) sand fraction: using 'Gibbs type' settling column at $1 / 4 \varnothing$ intervals; and (3) siltclay fraction: using pipette at $1 \varnothing$ intervals (Gama 2005).

Beach samples were analyzed using dry sieving at $1 / 2 \varnothing$ intervals (Gama 2005). The GRADISTAT program calculated the granulometric data parameters (Blott and Pye 2001). The weight difference after $\mathrm{CaCO}_{3}$ removal by acidic washing $(10 \% \mathrm{HCl})$ determined the carbonate content.

\subsection{Analytical Methods}

\subsubsection{Grain Size Trend Analysis (GSTA)}

\subsubsection{McLaren-Bowles Model}

Granulometric parameters commonly indicate the sediment transport direction. According to McLaren and Bowles (1985), the net sediment transport direction is inferred when the mean grain-size in a sample sequence becomes (1) finer, well sorted and more negatively skewed (FB-, low-energy transport); or (2) coarser, well sorted and more positively skewed ( $\mathrm{CB}+$, high-energy transport). Three parameters between each pair of samples are compared along the tested sample sequence. The process obtains the frequencies of occurrence for cases FB- and $\mathrm{CB}+$ in either direction. If the frequency is higher than the threshold ( $95 \%$ confidence level), sediment transport can be accepted to have higher 
probability to occur along that direction. A Z-score test is used to examine whether the trend is statistically significant (McLaren and Bowles 1985). The samples along the survey line should not be smaller than 8 or 9 for statistical considerations. The model is developed and applied in McLaren and Beveridge (2006) and McLaren et al. (2007).

\subsubsection{Gao-Collins Method}

Similar to the McLaren-Bowels model the transport vector in the Gao-Collins method is obtained based on granulometric parameters. Differently, the parameters comparision exists only in neghboring stations identified by a characteristic distance $\left(\mathrm{D}_{\mathrm{cr}}\right)$, defined by the maximum sampling interval. Within the characteristic distance, if either trend cases FB- or $\mathrm{CB}+$ is indentified to exist between two adjacent sampling sites, a dimensionless trend vector is defined whose length is assumed the unit length. A net vector is then obtained by summing all of the trend vectors among a particular site and its adjecent sites. The net vectors from adjacent sample sites are vectorially averaged to eliminate noise and the residual vectors may indicate the sediment transport trend (Gao and Collins 1992, 1994; Gao 1996). The Fortran code method is given by Gao (1996). The transport vector significance was tested using the modified Fortran code. The sediment transport trend significance is tested using the grain-size parameters at the orginal sampling stations randomly re-allocated to other stations to produce many empirical data sets to re-calculate the residual vectors according to the Gao-Collin method. This action was repeated 99 times obtaining a series of vectors at each station to provide a frequency distribution for the vector lengths. A critical length $\mathrm{L}_{\mathrm{x}}\left(\mathrm{L}_{95}\right.$ with a one-tailed $95 \%$ confidence interval) was then defined and the transport trend deemed significant if the vector lengths are greater than $L_{x}$ (Chang et al. 2001).

\subsubsection{EOF Analysis}

The sediment grain-size spatial distribution is the result of the combined influence of sediment sources and transport processes (Liu et al. 2000, 2002). In any marine system the interplay among sediment sources and hydrodynamic processes on different time and space scales is complex. Since the nature of the sediment data is multivariate, showing correlations among the sampling locations (space correlated) and different grain-size classes (size correlated), the EOF analysis technique was used to separate orthogonal modes contained in the data sets (Liu and Hou 1997). Eigen-modes were ranked according to the amount of data they explained and the better correlated the data, the more correlation is accounted for in the first few Eigen-modes. Each Eigen-mode also reveals a certain type of grain-size grouping and its corresponding spatial associations that might have process implications.

With two capes at both ends confining along shore sediment transport within the embayment, two hypothetical sediment sources were likely to influence the observed sediment distribution patterns. They include sediment from the tidal inlet at Tróia near the northern extremity of the embayment and cliff erosion in the southern part of the embayment. The grain-size sources were characterized by surface samples taken around the inlet and along the backshore in front of the cliffs. Based on the filtering concept proposed by Liu et al. $(2000,2002)$ the sediment data-processing flowchart is shown in Fig. 2. According to Liu and Zarillo (1990), in the deviation field, such as cliff-filtered deviation, the influence of cliff erosion was subtracted (minimized) so that the remaining data became more sensitive to the influence of other factors (such as inlet sediment) and the efficiency of the Eigen-modes reflects the cliff erosion influence on the data. The resulting Eigen function parameter spatial distribution (Eigen vectors and Eigen weightings) on the clifffiltered deviation field will reveal the tidal inlet sediment influence on the data (Liu and Zarillo 1990).

\section{RESULTS}

\subsection{Beach Sediment Analysis}

Figure 3 shows the $\mathrm{CaCO}_{3}$ content and grain size composition on the beach berm. These data were analyzed by The EOF method analyzed the data to decipher the relationships among the size-classes and their spatial variability to assess the study area littoral system sediment dynamics. The berm data percentages explained using the first three Eigen-modes are 41.8, 26.6, and 15.0\%, respectively. Each Eigen vector divides the sediment grain-size classes into two groups (Fig. 4). Eigen weightings in Eigen-mode 1 describe the southward coarser fraction decreasing trend (from coarse sand, to very fine gravel) while the finer fraction (finer than or equal to medium sand) increases having two zero-crossings at $\mathrm{p} 1$ and $\mathrm{p} 2$. The spatial variability southward from $\mathrm{p} 2$ is dominated by the coarser group, northward from $\mathrm{p} 1$ is dominated by the finer group while neither group has dominance between $\mathrm{p} 1$ and $\mathrm{p} 2$ (Fig. 5a). A positive correlation exists between the fine fraction and $\mathrm{CaCO}_{3}$. Eigenmode 2 might describe very fine gravel and very coarse sand lag deposits in the southern part of the shoreline. Coarse and medium sand are winnowed out and transported northward, the demarcation between the lag and winnowed deposits are around $\mathrm{p} 2$ (Fig. 5b), possibly reflecting the decreasing wave energy. The third Eigen-mode indicates that very fine gravel dominates the southern extremity, ending at $\mathrm{p} 3$ zero-crossing (Fig. 5c). A positive correlation exists between medium sand and $\mathrm{CaCO}_{3}$ in this mode indicating the source and sink aspect of $\mathrm{CaCO}_{3}$. The sharp change in these modes at the northern study area extremity points to the much-localized appearance of mud indicating the inlet sediment influence.

We divided the shoreline into four segments according to these spatial partitions, namely S1 - S4 from south 
to north (Fig. 5c). Referring to the original data (Fig. 3) the fining trend from south to north might indicate along shore transport such that fine-grained sediment is winnowed from the southern shoreline and transported to the north. In conjunction with medium sand, $\mathrm{CaCO}_{3}$ could be winnowed from S1 and S2 and transported to S4. Sediment composition on the beach berm in these segments could reflect the sediment transport trend.

\subsection{The Grain-Size Distribution on the Inner Shelf}

The abundance of pebbles, sand, silt and clay in weight (\%) and the granulometric parameters (mean grain-size, sorting, and skweness) of the ensemble data are plotted over

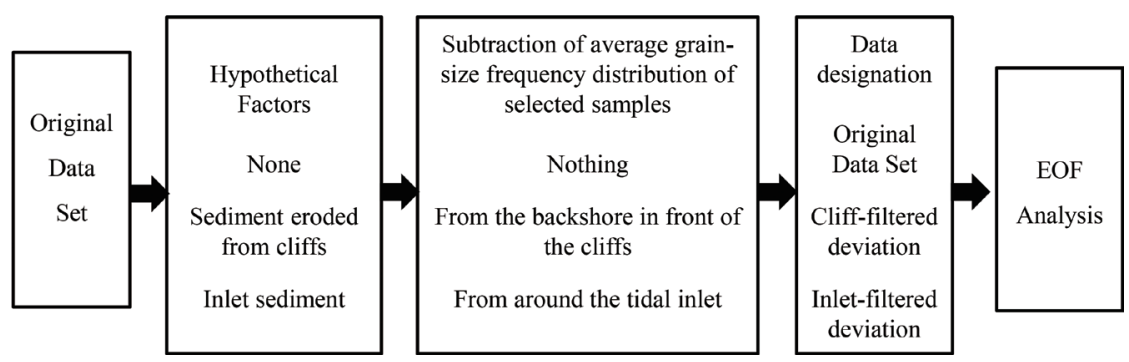

Fig. 2. Flow chart for the grain-size analysis that applies the filtering concept in the EOF technique.

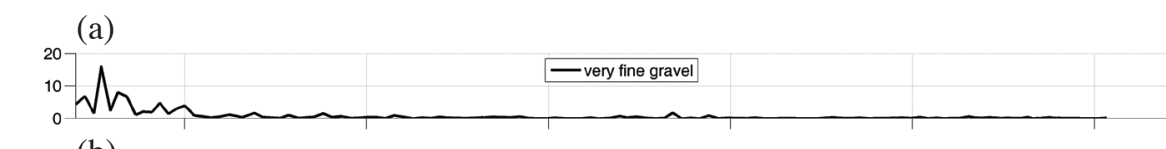

(b)

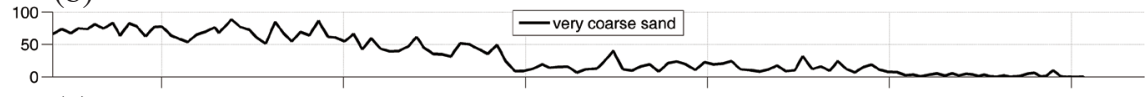

(c)
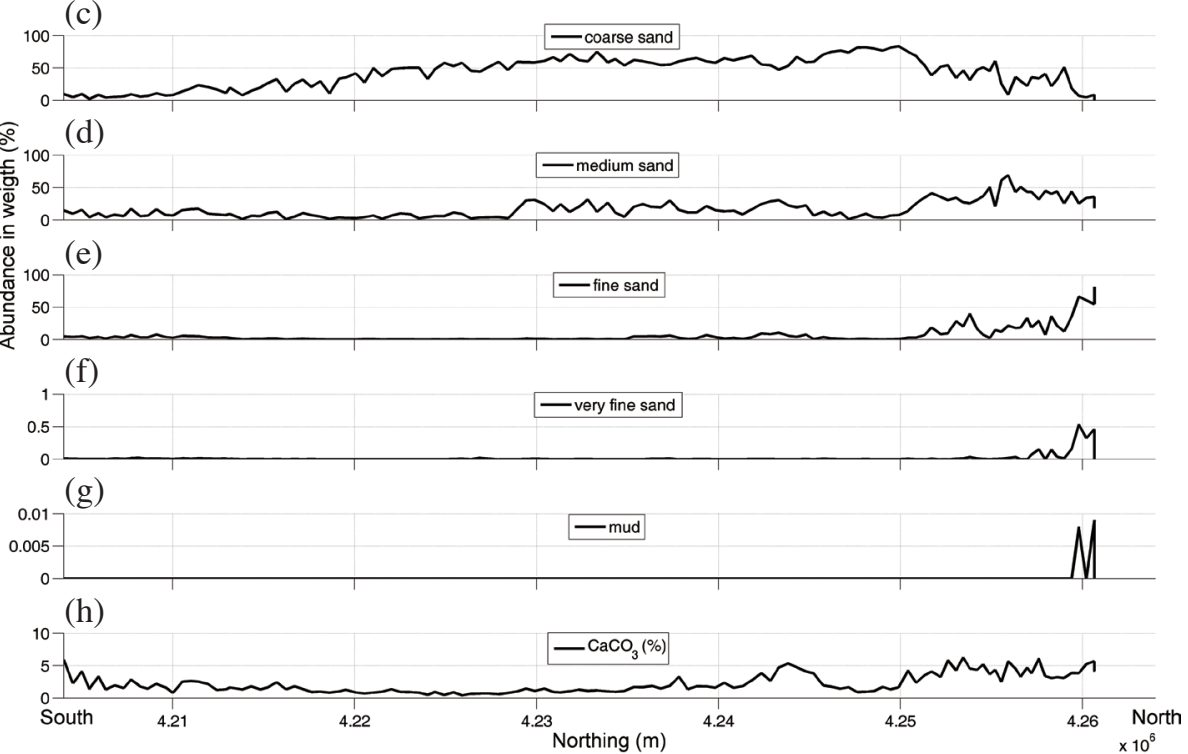

Fig. 3. Abundance (weight \%) of very fine gravel (a), very coarse sand (b), coarse sand (c), medium sand (d), fine sand (e), very fine sand (f), mud $(\mathrm{g})$, and $\mathrm{CaCO}_{3}(\mathrm{~h})$ on the berm along the shoreline. The southern end is on the left, the northern end is on the right.

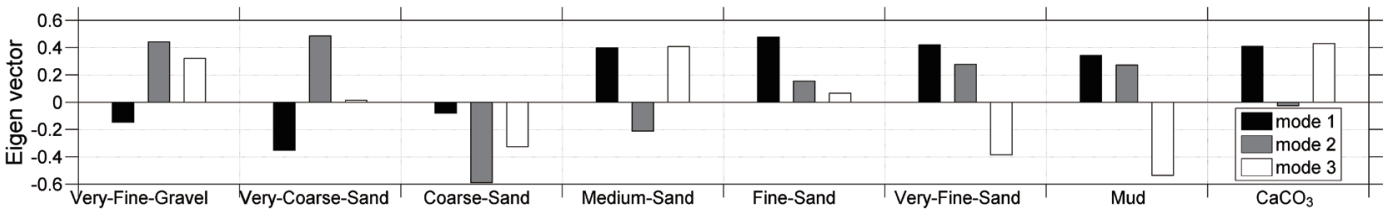

Fig. 4. Berm sample EOF analysis results and Eigen vectors for the frist three modes 


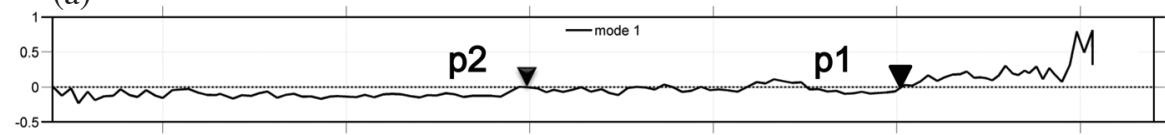

(b)

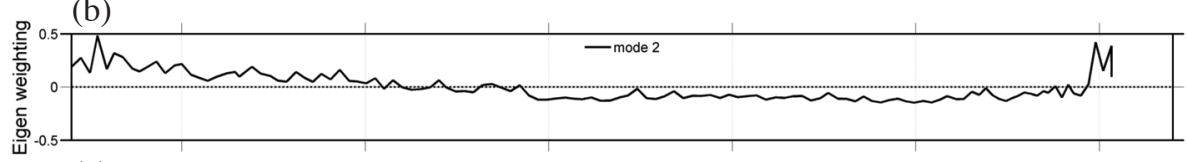

(c)

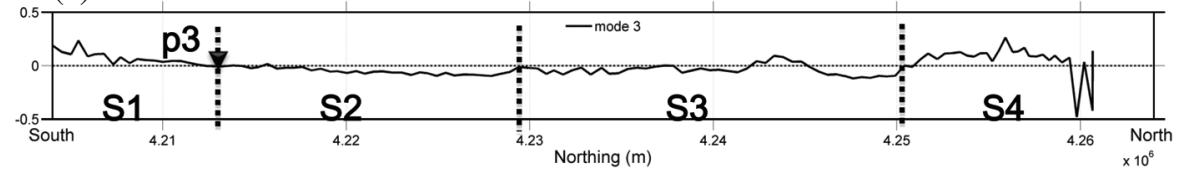

Fig. 5. Berm sample EOF analysis results and Eigen weightings in mode 1 (a), in mode 2 (b), and in mode 3 (c). The shoreline is divided into 4 segments according to the zero-crossing locations p1 - p3 (see details in text).

isobaths (Figs. 6 - 7). The grain size spectrums at some typical sites (at four profilers) are shown in Fig. 8. Sand is the most abundant and the most widely distributed size-class, having an abundance of more than $90 \%$ on the ebb-tidal delta and in the near shore area where the pebble abundance is less than $10 \%$ (Figs. 6a - b). The sediment is well sorted and symmetrical, ranging from 0 - $1 \varnothing$ (Figs. 7, 8a, c - f), as P1-1, P2-1, P2-2, P3-1, and P4-1 shown. Several patches of coarse sediment appear on submarine terraces on the middle shelf with sand abundance around $70 \%$ and pebble abundance around 30\% (Figs. 6a - b). According to Quevauviller (1987), these features delineate a paleo-shoreline. The sediment here is the coarsest in the study area (Figs. 7 - 8). In region 3 (see Fig. 1b), sand is less than $40 \%$, whereas silt and clay are the highest, reaching 30 and $40 \%$, respectively (Fig. 6). This is a unique area where sediment is the finest, the most poorly sorted, and generally positively skewed (Figs. 7 - 8), as P1-2 shown.

The representative grain-size composition of the two hypothetical sources are similar and yet distinguishable (the location of the sites see Fig. 8a). The sediment from cliff erosion has the highest sand abundance, reaching $99 \%$, without mud content (Fig. 8b). In contrast, notable silt and clay abundance exists in the inlet sediment.

\subsection{Sediment Transport Vector}

The offshore sampling stations in this study were nearly equally spaced, with the charcateristic distance $3408 \mathrm{~m}$. The statistically significant sediment transport vectors plotted over bathymetric contours show that sediment transport occurs in 4 areas (Fig. 9). In the offshore zone NW of Ribeirade Moinhos, the net sediment transport is directed mostly offshore. The inner shelf sediment in the Sines Cape vicinity is transported north along the shore. Note that sediment transports offshore between Santo Andre and Aberta Nova. Conversely, onshore sediment transport takes place land ward of the canyon head. In the northern embayment, sediment transport trends around the ebb-tidal delta including seaward movement via the tidal inlet and inlet-directed movement on margins of the ebb-tidal delta and tidal inlet, due to the northward littoral drift and ebb dominance on the flanks of a tidal inlet (Oertel 1988).

\subsection{Sediment Transport Pathways Deduced from Mclaren-Bowles Model}

We set 16 survey lines in this study area to study the along shore sediment transport. Among these 16, 8 lines were identified as having their Z-cores exceeding the significance level (as Fig. 10 shown). The McLaren-Bowles model results show that different transport pathways exist in the near shore and offshore zones, demarcated by closure depth. Significant high-energy northward sediment transport occurs in the near shore. On the south side of the canyon head, both northward and southward high-energy sediment transports exist due to persistent waves from the NW and storm waves and/or swells from the SW. However, sheltered from the NW waves, the northern embayment is only subject to the SW storm-induced currents and along shore drift, which transports sediment northward.

\subsection{EOF Analysis of the Shelf Data Sets}

Table 1 lists the percentages of data explained by the first two Eigen-modes for all deviation fields. The results show that the cliff-filtered (deviation from the representative cliff gain-size composition) improves the percentage explained by the first two Eigen-modes. In other words, it is better correlated than the original (unfiltered) data set (Table 1). This means the sediment eroded from cliffs is an important factor influencing the grain-size distribution in the study area (Liu et al. 2000, 2002), implying the cliffs are important sediment sources in the system. The inlet-filtered deviation field is less correlated than the original data, suggesting that the sediment 
exported out of the inlet is not a significant source for the entire system.

Figures 11 and 12 show first two modes for the Eigen vector and corresponding Eigen weighting plots for all deviation fields (the unfiltered data, cliff-filtered, and inlet-filtered). The Eigen vectors divide the sediment size-classes into two groups according to their signs (Figs. 11a-c, 12a-c). The spatial correspondence of the two groups is expressed by the Eigen weightings in a colored pattern whose values are indicated by the color bar in each plot (Figs. 11d - f, 12d - f). The positive grain-size group is weighted in the region with positive weightings and vice versa, separated by a thick solid line.

The first mode accentuates the sand variability as the sole size-class in the negative group (Figs. 11a - c). The positive areas in the corresponding Eigen weighting plots suggest areas where sand is relatively less abundant, such as on the terraces and the ebb-tidal delta front in region 3 (Figs. 11d - f). Sand is dominant elsewhere, generally in the nearshore zone, including the ebb-tidal delta (regions 1 and 2). Since the cliffs are the main sources for sand, the Eigen weightings in the cliff-filtered deviation (Fig. 11c) only show the presence of the unfiltered grouping (the other three size-classes, Fig. 11b).

The second mode accentuates the pebble variability as the sole size-class in the negative group (Figs. 12a - c). The pebbles are abundant mostly on the submarine terraces and therefore, corresponding to the negatively weighted areas in the offshore zone (Figs. 12d - f). The terrace association with the paleo-shorelines suggests the pebbles might be relict deposits (Figs. 12d - f). The EOF results reconfirm that sand
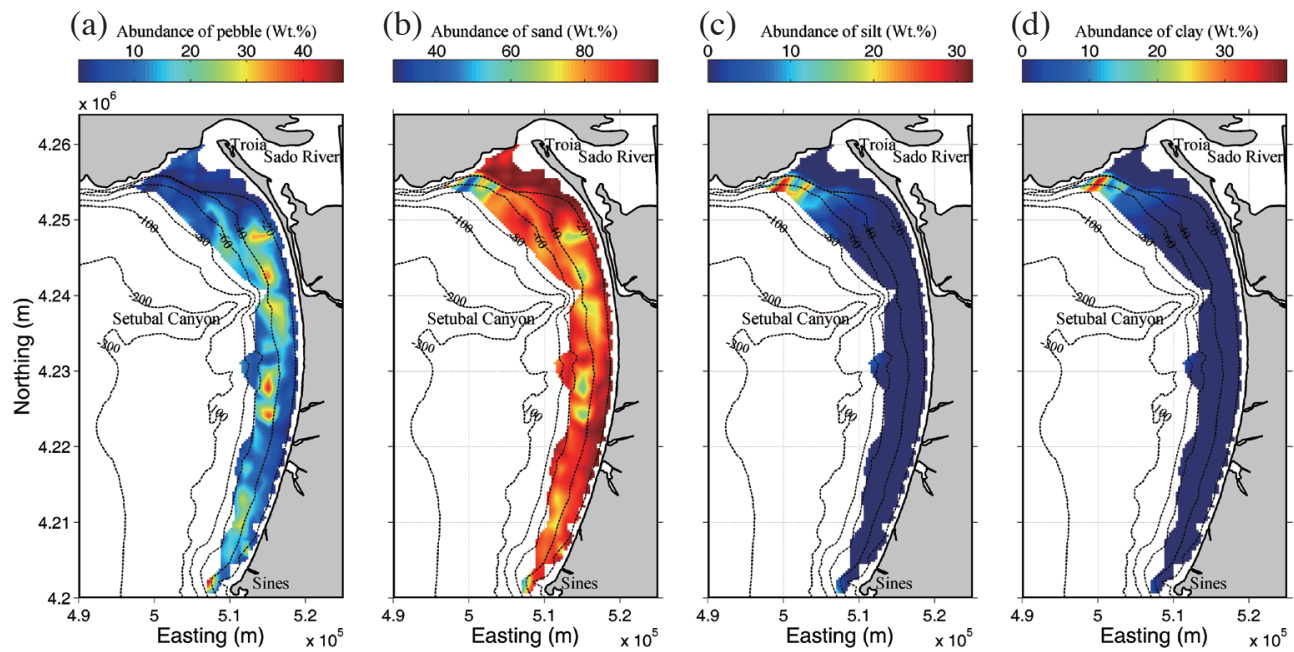

Fig. 6. Distribution pattern plots over the baythymetric contours of pebble (a), sand (b), silt (c), and clay (d), respectively. The abundance (weight $\%$ ) of each size class is indicated by the color bar on the top.
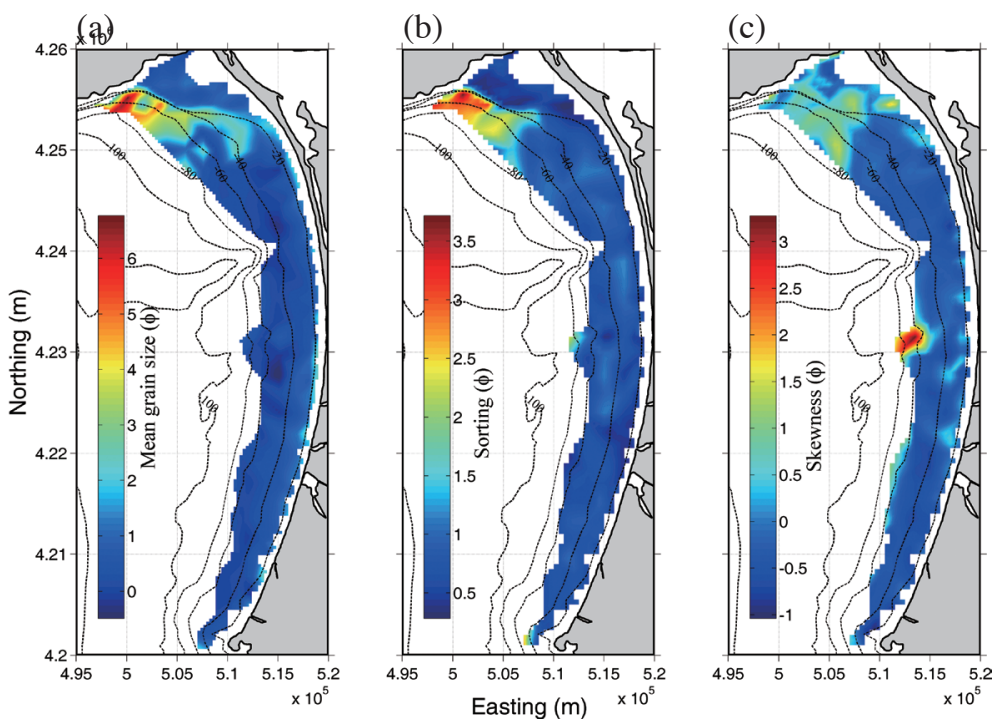

Fig. 7. The mean grain-size spatial distribution (a), sorting (b), and skewess (c). 


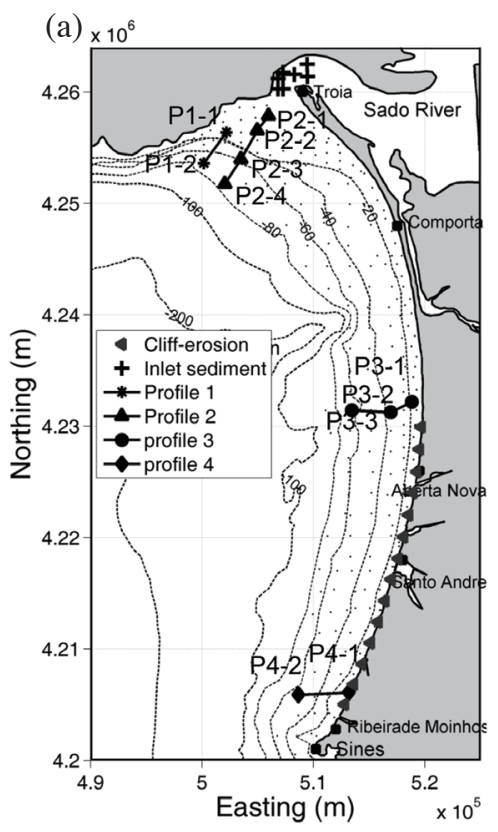

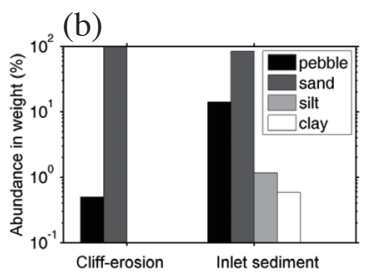

(d)

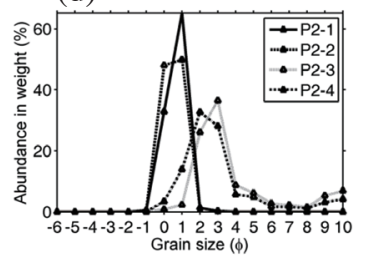

(f)

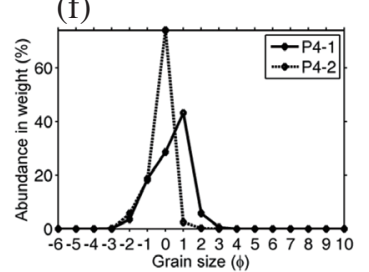

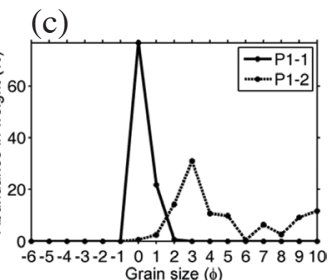

(e)

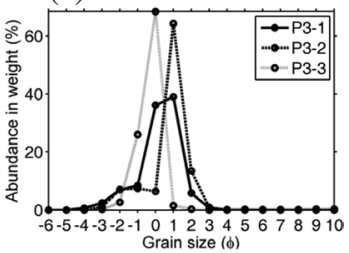

Fig. 8. The locations where sediment is chosen to represent cliff erosion (solid triangle) and inlet sediment (cross) and the sites to present the grain size spectrum (a); characteristic grain-size compositon of the two important sediment sources (b); grain-size distribution curves of four profilers (c) - (f).

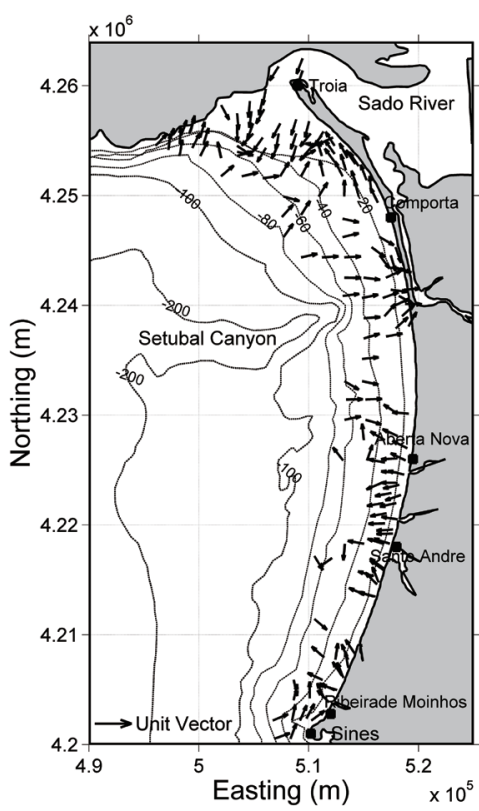

Fig. 9. Sediment transport vectors in the study area deduced from the Gao-Collins model.

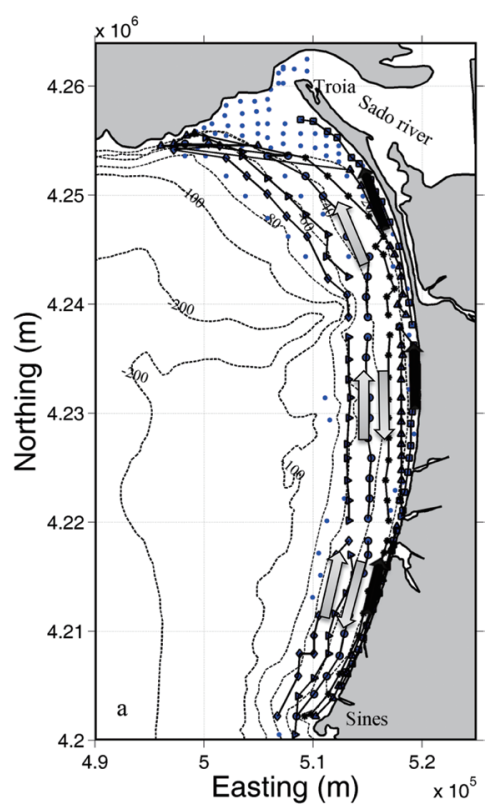

Fig. 10. Sediment transport pathways in the nearshore area (black arrows) and offshore zones (gray arrows) deduced from the McLaren model.

Table 1. Percentage of data explained by the first two Eigen-modes.

\begin{tabular}{cccc}
\hline Deviation field & Mode 1(\%) & Mode 2 (\%) & Cumulative (\%) \\
\hline Unfiltered data & 65.12 & 33.93 & 98.94 \\
Cliff-filtered & 68.02 & 31.00 & 99.02 \\
Inlet-filtered & 61.88 & 37.03 & 98.91 \\
\hline
\end{tabular}



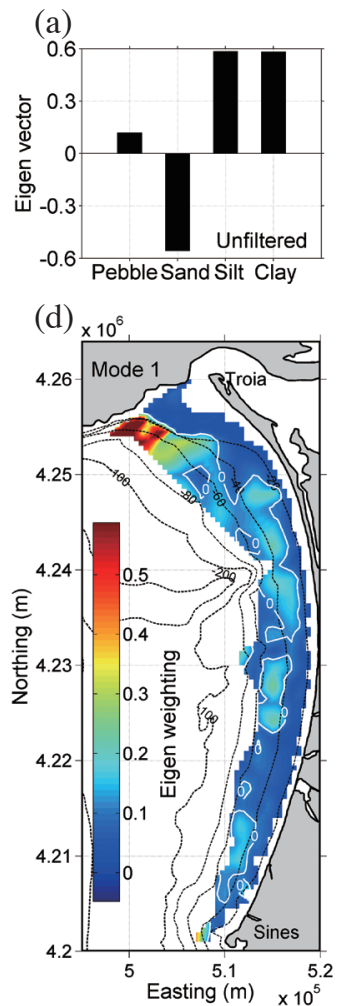

(b)

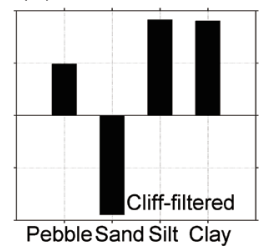

(e)

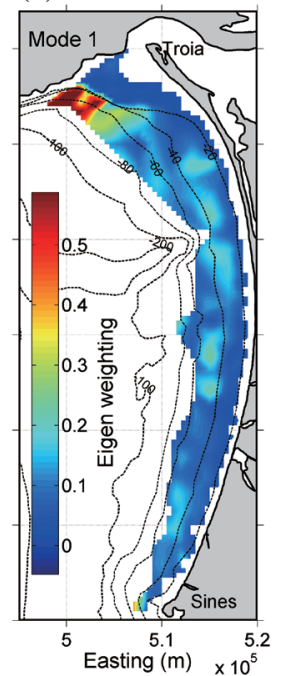

(c)

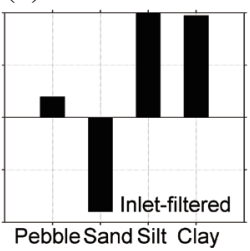

(f)

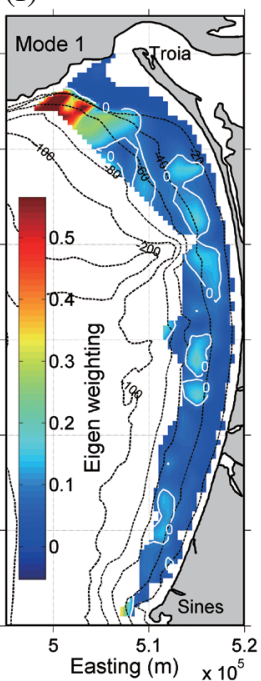

Fig. 11. EOF analysis results of different grain-size data sets (based on the flow chart shown in Fig. 2) for Eigen-mode 1. Eigen vectors (top) and Eigen weightings (bottom) of (a), (d) unfiltered data set; (b), (e) cliff-filtered; and (c), (f) inlet-filtered deviations, respectively.
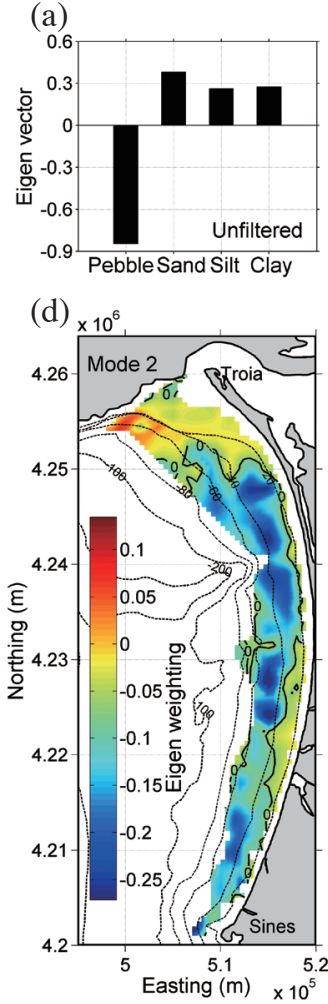

(b)

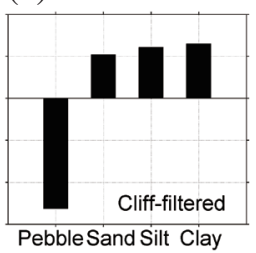

(e)

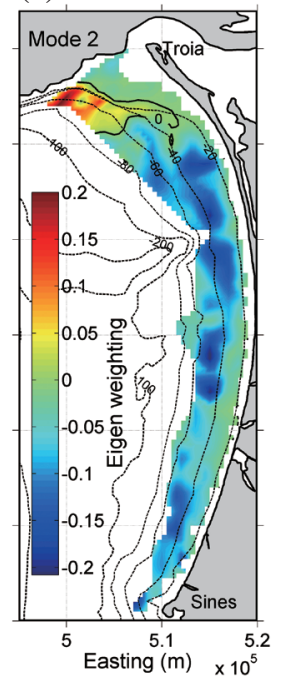

(c)

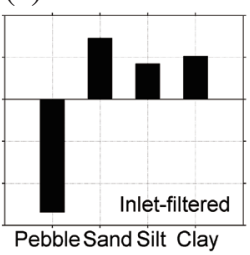

(f)

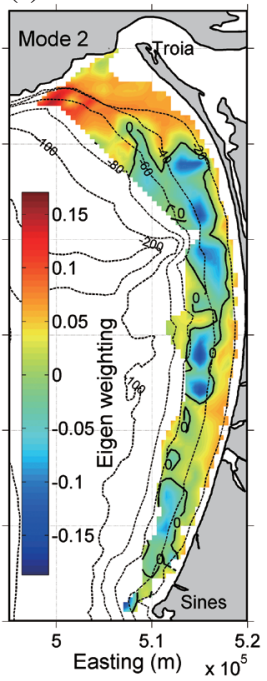

Fig. 12. EOF analysis results for different grain-size data sets (based on the flow chart shown in Fig. 2) for Eigen-mode 2. Eigen vectors (top) and Eigen weightings (bottom) of (a), (d) unfiltered data set; (b), (e) cliff-filtered; and (c), (f) inlet-filtered, respectively. 
eroded from cliffs is the most important sediment source, dominating the textural pattern in the littoral zone. The inlet sediment has only localized influence in the ebb-tidal delta.

\section{DISCUSSION AND CONCLUSION}

\subsection{Sediment Transport}

In the Gao-Collins model compares the grain size trends (cases FB- and $\mathrm{CB}+$ ) at a given site with the adjacent samples, opposite transport directions coexist, the two vectors cancel each other, and the sum is zero. Therefore, 'gaps' are present in the resultant plot (Fig. 9). Previously determined subaerial beach berm data segments S1 - S4 corroborate the transport vectors distribution (Figs. 4, 5, and 9). The spatial variability in the berm sediment distribution is part of the sediment transport patterns in the coast system.

The net cross-shore sediment transport in the southern part of the system is seawards. Backstrom et al. (2009) reported that subaerial beach erosion occurs during storms, and the eroded sediment is transported offshore by downwelling currents formed by coastal set up, caused by onshore winds and waves. However, it is difficult to mobilize coarser sediment grains in deeper water during fair weather. The sandy shelf in the southern embayment are exposed to the predominant waves from NW and more energetic but less frequent storms coming from $\mathrm{SW}$, which lead to southward and northward currents, respectively. Accordingly, bidirectional transport occurs along the shoreline. Sediment eroded from the cliffs could be transported northward by wave-induced currents, supplying sediment to the northern embayment. Sediment from the cliff-erosion via littoral drift controls the barrier spit elongation, which is a sink.

Transport vectors around the canyon head show landward sediment transport. As Jacob et al. (2009) reported, propagating over the canyon, storm waves from NW to $\mathrm{W}$ experience refraction, leading to spatial variation in wave heights and waves become weaker landward of the canyon head. Combined with upwelling, wave-induced currents move sediment towards the shoreline, causing convergence in the onshore sediment transport.

The northern embayment contains a mixed-energy environment of waves and tides, sheltered from the NW waves and exposed to less frequently but more energetic SW storm waves. Sediment transport patterns around the ebb-tidal delta include seaward sediment discharge from the inlet and inletdirected transport. However, the alongshore transport on the north side of the tidal inlet is probably weak, driven by refracted waves, causing an area of deposition (region 3 ) as evident by the relative high abundance of mud (Figs. $6 b-c$ ), which forms a mud sink in the system.

\subsection{Sediment Source}

This embayed system is a high-energy sandy environ- ment with one major and one minor sediment sources. The EOF results suggest cliff erosion is the most important in sediment supply to the entire study area and the sediment exported from the tidal inlet has only local influence. In the first mode, the abundance of sand causes the deviation and the cliff-filtered deviation explains more correlations than the unfiltered data set, implying cliff erosion plays an important role in supplying sand to the system. This process is as follows: down-welling currents generated by coastal setup during storms, carry sediment eroded from the cliffs seaward across the shore. Storm-induced currents also transport sand alongshore, so it is widely distributed on the inner shelf. The abundance of pebbles causes the deviation in the second mode. The inlet-filtered deviation explains more information than the unfiltered and cliff-filtered deviations, suggesting that sediment exported from the inlet is the second most important source. However, as reported by Jouanneau et al. (1998), the fluvial flow could not transport sediment coarser than coarse sand. Therefore, the higher pebble content at the inlet is probably channel lag deposits, caused by sorting tidal flows through and around the inlet. Without other immediate sources the mud at the ebb-tidal delta front (region 3) should be sourced from the Sado Estuarine. Since the contaminants tend to adsorb onto finer particles, region 3 is a sink for heavy metals. As mentioned in previous studies, submarine canyon is possibly another river and shelf sediment sink (Liu et al. $2002,2009)$. We could not verify this assertion because we do not have data from inside the canyon. Altogether, cliff erosion is the most significant sediment source for the coastal embayment. The cliffs provide most of sand on the inner shelf and the tidal flat. The minor source is sediment discharged from the tidal inlet for the delta front (region 3 ).

We integrated all of the results into a conceptual model for the sources and sediment transport in the embayed system. As shown in Fig. 13, this coastal system contains a complete

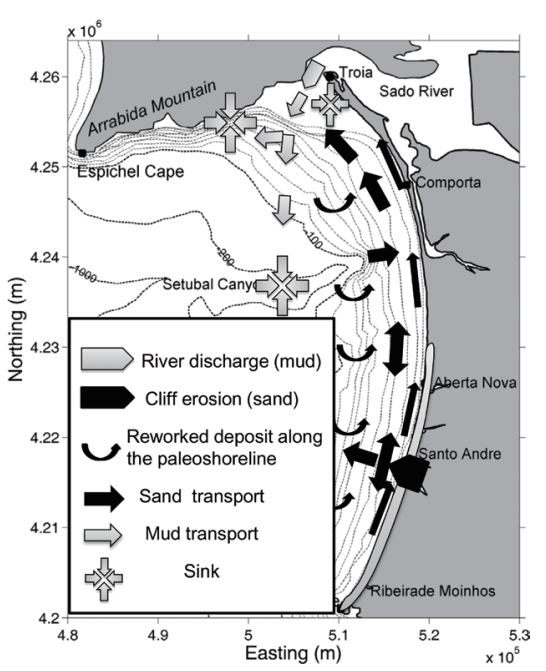

Fig. 13. Embayed system conceptual model for the sources, sinks and sediment transport patterns. 
sedimentation cycle, including sources (cliffs erosion and inlet export), sinks (the barrier spit, the ebb-tidal delta and delta front region, and the submarine canyon), and transport pathways (littoral drift in the nearshore zone, seaward transport on the ebb-tidal delta, shore-parallel and shore-perpendicular transports in the offshore zone). This model provides useful insight into the coastal system at TSEC.

Acknowledgements The study was funded by the R.O.C. National Science Council under grant numbers NSC99-2611-M-110-005. We acknowledge the Institute Hydrographic of Portugal for providing the grain-size shelf data. Paulo Baptista was supported by the Fundação para a Ciência e a Tecnologia, grant reference SFRH/BPD/63141/2009. We thank Ray Hsu, Peter Huang and Wayne Chen for their assistance in manuscript preparation. We are grateful to the Associate Editor and the Anonymous Reviewers for their helpful comments and suggestions in improving this manuscript.

\section{REFERENCES}

Asselman, N. E. M., 1999: Grain-size trends used to assess the effective discharge for floodplain sedimentation, River Waal, the Netherlands. J. Sediment. Res., 69, 51-61.

Backstrom, J. T., D. W. T. Jackson, and J. A. G. Cooper, 2009: Shoreface morphodynamics of a high-energy, steep and geologically constrained shoreline segment in Northern Ireland. Mar. Geol., 257, 94-106, doi: 10.1016/j.margeo.2008.11.002. [Link]

Blott, S. J. and K. Pye, 2001: GRADISTAT: A grain size distribution and statistics package for the analysis of unconsolidated sediments. Earth Surf. Process. Landf., 26, 1237-1248, doi: 10.1002/esp.261. [Link]

Carvalho, C., R. M. Anjos, R. Veiga, and K. Macario, 2011: Application of radiometric analysis in the study of provenance and transport processes of Brazilian coastal sediments. J. Environ. Radioact., 102, 185-192, doi: 10.1016/j.jenvrad.2010.11.011. [Link]

Chang, Y. H., M. D. Scrimshaw, and J. N. Lester, 2001: A revised Grain-Size Trend Analysis program to define net sediment transport pathways. Comput. Geosci., 27, 109114, doi: 10.1016/S0098-3004(00)00065-0. [Link]

Cheng, P., S. Gao, and H. Bokuniewicz, 2004: Net sediment transport patterns over the Bohai Strait based on grain size trend analysis. Estuar. Coast. Shelf Sci., 60, 203212, doi: 10.1016/j.ecss.2003.12.009. [Link]

Costa, M., R. Silva, and J. Vitorino, 2001: Contribuição para o estudo do clima de agitação marítima na costa portuguesa. Actas das 2as Jornadas Portuguesas de Engenharia Costeira e Portuária (Sines, Associação Internacional de Navegação), CD-ROM.

Freitas, M. C., C. Andrade, A. Cruces, J. Munhá, M. J. Sousa, S. Moreira, J. M. Jouanneau, and L. Martins, 2008: Anthropogenic influence in the Sado estuary
(Portugal): A geochemical approach.J.Iber. Geol., 34, 271-286.

Gama, C., 2005: Dynamics of sediment systems in the western coast of Portugal south cape Espichel. Ph.D. Thesis, University of Évora, Évora, Portugal.

Gao, S., 1996: A FORTRAN program for grain-size trend analysis to define net sediment transport pathways. Comput. Geosci., 22, 449-452, doi: 10.1016/00983004(95)00100-X. [Link]

Gao, S. and M. Collins, 1992: Net sediment transport patterns inferred from grain-size trends, based upon definition of "transport vectors". Sediment. Geol., 80, 4760, doi: 10.1016/0037-0738(92)90055-V. [Link]

Gao, S. and M. Collins, 1994: Net sediment transport patterns inferred from grain-size trends, based upon definition of "transport vectors"-reply. Sediment. Geol., 90, 157-159, doi: 10.1016/0037-0738(94)90023-X. [Link]

Gao, S., M. Collins, P. McLaren, and D. Bowles, 1991: A critique of the "McLaren Method" for defining sediment transport paths; discussion and reply. J. Sediment. Res., 61, 143-147, doi: 10.1306/D42676A92B26-11D7-8648000102C1865D. [Link]

Gao, S., M. B. Collins, J. Lanckneus, G. De Moor, and V. Van Lancker, 1994: Grain size trends associated with net sediment transport patterns: An example from the Belgian continental shelf. Mar. Geol., 121, 171-185, doi: 10.1016/0025-3227(94)90029-9. [Link]

Hallermeier, R. J., 1981: A profile zonation for seasonal sand beaches from wave climate. Coast. Eng., 4, 253 277, doi: 10.1016/0378-3839(80)90022-8. [Link]

Harzen, S., 1998: Habitat use by the bottlenose dolphin (Tursiops truncatus) in the Sado estuary, Portugal. Aquat. Mammals, 24, 117-128.

Héquette, A., Y. Hemdane, and E. J. Anthony, 2008: Determination of sediment transport paths in macrotidal shoreface environments: A comparison of grain-size trend analysis with near-bed current measurements. J. Coast. Res., 24, 695-707, doi: 10.2112/06-0714.1. [Link]

Horng, C. S. and C. A. Huh, 2011: Magnetic properties as tracers for source-to-sink dispersal of sediments: A case study in the Taiwan Strait. Earth Planet. Sci.Lett., 309, 141-152, doi: 10.1016/j.epsl.2011.07.002. [Link]

Huh, C. A., W. Chen, F. H. Hsu, C. C. Su, J. K. Chiu, S. Lin, C. S. Liu, and B. J. Huang, 2011: Modern $(<100$ years) sedimentation in the Taiwan Strait: Rates and source-to-sink pathways elucidated from radionuclides and particle size distribution. Cont. Shelf Res., 31, 4763, doi: 10.1016/j.csr.2010.11.002. [Link]

Jacob, J., C. Gama, R. Salgado, J. T. Liu, and A. Silva, 2009: Shadowing effects on beach morphodynamics during storm events on Tróia-Sines embayed coast, southwest Portugal. J. Coast. Res., SI56, 73-77.

Jouanneau, J. M., C. Garcia, A. Oliveira, A. Rodrigues, J. A. 
Dias, and O. Weber, 1998: Dispersal and deposition of suspended sediment on the shelf off the Tagus and Sado estuaries, S.W. Portugal. Prog. Oceanogr., 42, 233-257, doi: 10.1016/S0079-6611(98)00036-6. [Link]

Krumbein, W. C., 1938: Size frequency distributions of sediments and the normal phi curve. J. Sediment. Res., 8, 84-90, doi: 10.1306/D4269008-2B26-11D78648000102C1865D. [Link]

Le Roux, J. P., 1994a: Net sediment transport patterns inferred from grain-size trends, based upon definition of "transport vectors"-comment. Sediment. Geol., 90, 153-156, doi: 10.1016/0037-0738(94)90022-1. [Link]

Le Roux, J. P., 1994b: An alternative approach to the identification of net sediment transport paths based on grain-size trends. Sediment. Geol., 94, 97-107, doi: 10.1016/0037-0738(94)90149-X. [Link]

Liu, J. T. and G. A. Zarillo, 1990: Shoreface dynamics: Evidence from bathymetry and surficial sediments. Mar. Geol., 94, 37-53, doi: 10.1016/0025-3227(90)90102-P. [Link]

Liu, J. T. and L. Hou, 1997: Sediment trapping and bypassing characteristics of a stable tidal inlet at Kaohsiung Harbor, Taiwan. Mar. Geol., 140, 367-390, doi: 10.1016/S0025-3227(97)00027-3. [Link]

Liu, J. T., J. S. Huang, R. T. Hsu, and J. M. Chyan, 2000: The coastal depositional system of a small mountainous river: A perspective from grain-size distributions. Mar. Geol., 165, 63-86, doi: 10.1016/S00253227(99)00131-0. [Link]

Liu, J. T., K. Liu, and J. C. Huang, 2002: The effect of a submarine canyon on the river sediment dispersal and inner shelf sediment movements in southern Taiwan. Mar. Geol., 181, 357-386, doi: 10.1016/S00253227(01)00219-5. [Link]

Liu, J. T., J. J. Hung, H. L. Lin, C. A. Huh, C. L. Lee, R. T. Hsu, Y. W. Huang, and J. C. Chu, 2009: From suspended particles to strata: The fate of terrestrial substances in the Gaoping (Kaoping) submarine canyon. J. Mar. Syst., 76, 417-432, doi: 10.1016/j.jmarsys.2008.01.010. [Link]

Ma, F., Y. Wang, Y. Li, C. Ye, Z. Xu, and F. Zhang, 2010: The application of geostatistics in grain size trend analysis: A case study of eastern Beibu Gulf. J. Geogr. Sci., 20, 77-90, doi: 10.1007/s11442-010-0077-1. [Link]

Marques, F. M. S. F., 1999: Evolução das arribas e da linha de costa no arco litoral Tróia-Sines (Portugal). Actas do Seminário "A zona costeira do Alentejo", Associação Eurocoast (Portugal), Sines 16-18 Junho.

Martins, F., P. Leitão, A. Silva, and R. Neves, 2001: 3D modelling in the Sado estuary using a new generic vertical discretization approach. Oceanol. Acta, 24, 51-62, doi: 10.1016/S0399-1784(01)00092-5. [Link]

McCave, I. N., 1978: Grain-size trends and transport along beaches: Example from eastern England. Mar. Geol., 28,
M43-M51, doi: 10.1016/0025-3227(78)90092-0. [Link]

McLaren, P., 1981: An interpretation of trends in grain size measures. J. Sediment. Res., 51, 611-624, doi: 10.1306/ 212F7CF2-2B24-11D7-8648000102C1865D. [Link]

McLaren, P. and D. Bowles, 1985: The effects of sediment transport on grain-size distributions. J. Sediment. Res., $\mathbf{5 5}, 457-470$.

McLaren, P. and R. P. Beveridge, 2006: Sediment trend analysis of the hylebos waterway: Implications for liability allocations. Integrated Environ. Assess. Manag., 2, e8-e 19, doi: 10.1002/ieam.5630020310. [Link]

McLaren, P., S. H. Hill, and D. Bowles, 2007: Deriving transport pathways in a sediment trend analysis (STA). Sediment. Geol., 202, 489-498, doi: 10.1016/j.sedgeo.2007.03.011. [Link]

Monteiro, M. T., R. Oliveira, and C. Vale, 1995: Metal stress on the plankton communities of Sado River (Portugal). Water Res., 29, 695-701, doi: 10.1016/00431354(94)00156-2. [Link]

Nicholls, R. J., W. A. Birkemeier, and G. Lee, 1998: Evaluation of depth of closure using data from Duck, NC, USA. Mar. Geol., 148, 179-201, doi: 10.1016/S00253227(98)00011-5. [Link]

Oertel,G.F., 1988: Processes of sediment exchange between tidal inlets, ebb deltas and barrier islands. In: Aubrey, D. G. and L.Weishar (Eds.), Hydrodynamics and Sediment Dynamics of Tidal Inlets, Springer-Verlag, New York, 297-318, doi: 10.1029/LN029p0297. [Link]

Pedreros, R., H. L. Howa, and D. Michel, 1996: Application of grain size trend analysis for the determination of sediment transport pathways in intertidal areas. Mar. Geol., 135, 35-49, doi: 10.1016/S0025-3227(96)000424. [Link]

Pettijohn, F. J. and J. D. Ridge, 1932: A textural variation series of beach sands from Cedar Point, Ohio. J. Sediment. Res., 2, 76-88, doi: 10.1306/D4268E0A-2B2611D7-8648000102C1865D. [Link]

Pettijohn, F. J., P. E. Potter, and R. Siever, 1972: Sand and Sandstone, Springer, New York, doi: 10.1007/978-14615-9974-6. [Link]

Plomaritis, T. A., D. Paphitis, and M. Collins, 2008: The use of grain size trend analysis in macrotidal areas with breakwaters: Implications of settling velocity and spatial sampling density. Mar. Geol., 253, 132-148, doi: 10.1016/j.margeo.2008.05.003. [Link]

Plumley, W. J., 1948: Black Hills terrace gravels: a study in sediment transport. J. Geol., 56, 526-577.

Poizot, E. and Y. Méar, 2008: eCSedtrend: A new software to improve sediment trend analysis. Comput. Geosci., 34, 827-837, doi: 10.1016/j.cageo.2007.05.022. [Link]

Poizot, E. and Y. Méar, 2010: Using a GIS to enhance grain size trend analysis. Environ. Modell. Softw., 25, 513525, doi: 10.1016/j.envsoft.2009.10.002. [Link]

Poizot, E., Y. Méar, M. Thomas, and S. Garnaud, 2006: The 
application of geostatistics in defining the characteristic distance for grain size trend analysis. Comput. Geosci., 32, 360-370, doi: 10.1016/j.cageo.2005.06.023. [Link]

Quevauviller, P., 1987: Etude geomorphologique, sedimentologique et geochimique du littoral de Galé et de l'estuaire du Sado (Portugal). Ph.D. Thesis, University of Bordeaux, Talence, France.

Rebêlo, L. P., M. Ferraz, and P. O. Brito, 2009: Tróia peninsula evolution: the dune morphology record. J. Coast. Res., SI56, 352-355.

Reis, A. H. and C. Gama, 2010: Sand size versus beachface slope - An explanation based on the Constructal Law. Geomorphology, 114, 276-283, doi: 10.1016/j. geomorph.2009.07.008. [Link]

Russell, R. D., 1939: Effects of transportation on sedimentary particles: Part 1. Transportation. In: Trask, P. D. (Ed.), Recent Marine Sediments, SEPM, Tulsa, OK, 32-47.

Shi, X., C. Chen, Y. Liu, H. Ren, and H. Wang, 2002: Trend analysis of sediment grain size and sedimentary process in the central South Yellow Sea. Chin. Sci. Bull., 47, 1202-1207, doi: 10.1007/BF02907610. [Link]

Swift, D. J. P., J. C. Ludwick, and R. W. Boehmer, 1972: Shelf sediment transport: A probability model. In: Swift, D. J. P., D. B. Duane, and O. H. Pilkey (Eds.), Shelf Sediment Transport: Process and Pattern, Dowden, Hutchinson and Ross, Troudsburg, PA, 145-224.

Syvitski, J. P. M., 2003: Supply and flux of sediment along hydrological pathways: Research for the 21 st century. Global Planet. Change, 39, 1-11, doi: 10.1016/S09218181(03)00008-0. [Link]

Syvitski, J. P. M., S. D. Peckham, R. Hilberman, and T. Mulder, 2003: Predicting the terrestrial flux of sediment to the global ocean: A planetary perspective. Sediment. Geol., 162, 5-24, doi: 10.1016/S0037-0738(03)00232X. [Link]

Vale, C., C. Cortesão, O. Castro, and A. M. Ferreira, 1993: Suspended-sediment response to pulses in river flow and semidiurnal and fortnightly tidal variations in a mesotidal estuary. Mar. Chem., 43, 21-31, doi: 10.1016/0304-4203(93)90213-8. [Link]

Wang, Y. P., S. Gao, J. Jia, C. E. L. Thompson, J. Gao, and Y. Yang, 2012: Sediment transport over an accretional intertidal flat with influences of reclamation, Jiangsu coast, China. Mar. Geol., 291-294, 147-161, doi: 10.1016/j.margeo.2011.01.004. [Link]

Wheater, H. S., A. J. Jakeman, and K. J. Beven, 1993: Progress and directions in rainfall-runoff modeling. In: Jakeman, A. J., M. B. Beck, and M. J. McAleer (Eds.), Modelling Change in Environmental Systems, John Wiley and Sons, Chichester, UK, 101-132.

Xu, K., J. D. Milliman, A. Li, J. P. Liu, S. J. Kao, and S. Wan, 2009: Yangtze- and Taiwan-derived sediments on the inner shelf of East China Sea. Cont. Shelf Res., 29, 2240-2256, doi: 10.1016/j.csr.2009.08.017. [Link] 